\title{
MOOTING IN AN UNDERGRADUATE TAX PROGRAM
}

\author{
DUNCAN BENTLEY*
}

\begin{abstract}
[Mooting is a common form of assessment in law schools. This paper examines the validity of using mooting as a form of assessment in any undergraduate tax program. The first part of the paper examines the skills required by tax professionals and whether mooting is a valid way to learn those skills. It also examines the educational validity of mooting as a form of instruction in an undergraduate tax program. The second part of the paper looks at the practical implementation of a mooting program. Mooting can be used as part of a skills program or can equally easily be adapted for use as a stand alone form of assessment. It can be formal or informal. One model of a mooting program is examined in the light of the underlying theory, from the writing of the moot problem through to assessment and feedback. The paper concludes by looking at the resource implications of a mooting program for tax students and problems that may arise.]
\end{abstract}

\section{INTRODUCTION}

moot: "students' discussion of hypothetical case for practice” (The Concise Oxford Dictionary)

The non-law schools have long recognised the importance of the legal element in their programs and some of the most reputable commercial legal scholars are found in the law discipline within those schools. There is also an increasing number of non-law students in commercial law subjects within law schools. One of the main subjects attracting students from a variety of disciplines is taxation. For various reasons, but probably at least in part because of its association with traditional law school subjects for lawyers, mooting is seldom used in the teaching of taxation. This paper examines whether mooting can be used usefully in an undergraduate taxation law program that includes, or is made up of, non-law students.

The first part of the paper reviews the skills that have been identified as being important to tax professionals, whether lawyers or non-lawyers. It looks at the development of those skills in the context of a mooting program and concludes that mooting is a valid method for developing many of the skills required of a tax professional, in whatever discipline the instruction takes place. The second part of the paper provides a detailed model of how a moot can be used as part of an undergraduate tax course in the light of the underlying theory. The paper concludes with a review of possible resource implications of implementing a mooting program and consideration of two particular problems that need to be dealt with.

\section{PART I: WHY MOOTING?}

\section{Background}

Mooting has long been the preserve of law schools and it is not generally found in tax and commercial law courses. Does this mean that mooting is a skill not required by business and tax professionals, particularly the vast majority who do not intend to practise law? Not necessarily Tax professionals are required to research, evaluate and analyse the law and administrative regulations. They are then required to express their views on the application of the law and administrative regulations, both in written and oral form, to clients and the relevant administrative and regulatory authorities. Accordingly, it is worth exploring whether mooting is a valid educational means of acquiring required skills and whether those skills are relevant to students of non-law disciplines. The journey starts in the legal literature, as in recent years considerable interest in this area by the legal profession has provided some useful insights. 
The Pearce Report into Australian Law Schools stated that: “[t]raditionally law schools have offered mooting programs which serve to develop a student's oral ability and make some gesture towards forensic training". ${ }^{1}$ The Report felt that the teaching of such skills was important, for "skills are of a high order and can be studied in some depth with insights being drawn from other areas of social sciences and the humanities". ${ }^{2}$ This view reflected that of the American Bar Association (ABA). In a 1980 ABA Report into law schools and professional education, a study by Zemans and Rosenblum was quoted with approval, in which a sample of Chicago attorneys identified those skills and areas of knowledge that they considered to be important to the practice of law. ${ }^{3}$ The top four of these were: fact gathering; a capacity to marshal facts and order them so that concepts can be applied; instilling others' confidence in you; and effective oral expression. As was pointed out in the report, these skills "involve intellectual or interpersonal skills that are not peculiar to the legal profession”. ${ }^{4}$ In a review of the types of skills considered important by specialty area, it was found that tax lawyers, not surprisingly gave "high evaluations to analytic and business skills". 5

The ABA published the MacCrate report in July $1992 .{ }^{6}$ The focus of the report was on the education of lawyers. As part of this focus the report produced a statement of fundamental lawyering skills and professional values. There is little new in this statement, but it is the clear articulation of the skills and values fundamental to most good law professionals that is useful, particularly for educators. It will be shown below that a number of the skills identified, namely: problem solving; legal analysis and reasoning; legal research; communication; and, to a limited extent, organisation and management of legal work, are both relevant to tax professionals and can be developed to some degree through a mooting program.

It is important to note that the skills identified as essential to good lawyering are not exclusive to the legal profession. The skills are often defined in different terms in other disciplines, but the content is essentially similar. For example: problem solving; legal analysis and reasoning; and legal research, have their equivalents expressed in the more comprehensive problem solving models of some other disciplines. The classical model of problem solving taught in most standard business textbooks would incorporate analysis, reasoning and research into the problem solving process. There are variations on a "rational, fourstep sequence: (1) identifying the problem, (2) generating alternative solutions, (3) evaluating and selecting a solution, and (4) implementing and evaluating the solution"7 Similar models are used by medical students, as described by Charles Engel of the London School of Hygiene and Tropical Medicine in his outline of a problem-based learning curriculum for first year medical students. ${ }^{8}$

Some contemporary models of the decision-making process eschew a structured model of problem solving. ${ }^{9}$ But as Kreitner and Kinicki conclude after discussing contemporary theories of decision-making, in what is a fairly standard text on organisational behaviour. ${ }^{10}$

Still, it is important to train managers in how to most effectively perform each stage of problem solving ... Further, since decision-making processes are activated by different organizational stimuli, it would be helpful for managers to know when a particular process is most effective. Organizations need to identify the decision-making processes they use on a regular basis. Managers can then be trained to use processes that are most effective for a particular situation.

A common theme coming out of the various disciplinary models, is that practitioners need training in how to develop the basic skills needed in their profession. This was reflected in the White Paper produced by an Institute of Chartered Accountants in Australia task force, that looked into the challenges faced by the profession into the 21st century. Among the skills that the White Paper identified as important for any chartered accountant to possess are: ${ }^{11}$

- sound technical accounting skills that would include an in-depth knowledge of one or more specialist accounting areas (one of these being tax in the context of this paper);

- excellent communication skills, enabling the accountant to listen effectively, present, discuss and defend views, write clear reports and communicate with clients from different cultures; and

- the intellectual ability to identify and solve problems and to handle ethical dilemmas.

One of the challenges facing teachers of prospective tax professionals is the inter-disciplinary nature of the subject. The list of skills that are important to the practice of any profession may be similar, but the exercise of those skills is generally slightly different. ${ }^{12}$ For example, the business decision- making process is at least contextually different from the legal decision-making process. However, tax professionals need a mix of legal and commercial skills. The tax barrister may use skills in a more legally oriented fashion than a 
tax accountant, but the interpretation and application of the tax law is fundamental to the practice of either.

Recognising the dilemma, John Prebble, ${ }^{13}$ in proposing a comprehensive conceptual framework of tax knowledge for any program of international tax education, said that the skills relevant to a tax professional should be learnt in conjunction with the teaching of that tax knowledge. ${ }^{14}$ This suggests that it is important that tax teachers in any discipline appreciate the particular skill requirements of the tax specialism. A 1994 report into Australian law schools after the Pearce Report found that law schools have indeed focussed on the development of their skills training programs in recent years. ${ }^{15}$ To what extent tax subjects have participated in this development of skills training programs is uncertain. It is clear that research is needed, to determine more precisely than does this paper, what are the particular skill requirements of tax professionals. The results will facilitate the tailoring of existing skills programs and the development of new programs to cater for the specific requirements identified.

However, it is already evident that particular research, problem solving and communication skills are required by tax professionals, whatever their discipline, and that tax teachers should be developing those skills as part of any tax teaching program. ${ }^{16}$ The next step is to determine in what ways these skills can be learnt.

\section{Skill Development}

Teaching someone a skill ... requires developing the learner's capacity to respond to the unexpected, to understand what he or she is doing and why, to be intelligent and reflective in the exercise of his or her skill. Such teaching therefore involves the giving of reasons ... ${ }^{17}$

All the lists of skills outlined in the previous section require critical thinking. Critical thinking can be defined as "the mental ability to deal reasonably and reflectively with questions about what to believe or do". ${ }^{18}$ It is identified by Prebble as one of the fundamental skills needed by a tax professional. ${ }^{19}$ Yet research has shown that critical thinking is not necessarily learnt through the traditional educational process.

Recent work by social and cognitive psychologists has found that adults use many flawed inferential strategies. These flawed inferential strategies would affect the ability to infer generalizations, to make predictions, and to evaluate, indicate reasons, and give explanations and definitions. ${ }^{20}$

Accordingly, it is vital that tax teachers adopt appropriate methodologies to enable students to learn the required skills. It is not sufficient to assume that students will simply "pick up" the skills. An added advantage of adopting different methodologies aimed at training a variety of skills is that it is both more effective and seen to be more effective by students. ${ }^{21}$ This is not surprising, given that: in their teaching model on how to improve thinking, based on Piaget's ideas, Joyce and Weil show how special learning environments need to be created for different kinds of knowledge and how the teacher must be flexible and responsive to encourage self-discovery learning. ${ }^{22}$

The MacCrate Report is more specific and states that effective teaching of the skills and values analysed in its Statement of Fundamental Lawyering Skills and Professional Values would usually involve three components: ${ }^{23}$

- Development of concepts and theories underlying the skills and values being taught;

- Opportunity for students to perform lawyering tasks with appropriate feedback;

- Reflective evaluation of the students' performance by a qualified assessor.

In summary, so far, we have seen that tax professionals require skills training and that skills training is more likely to be successful if the training medium specifically focuses on developing the required skill. This means that a variety of methodologies will, of necessity, be included in any teaching program, in order to develop a variety of skills in the students. The question then relevant here is, is mooting a valid method for developing the skills required of a tax professional? The answer to this is determined in the context of an examination of the possible components of a mooting program.

\section{Mooting and Skills Development}

Although there has been significant debate as to the value of setting instructional objectives, most teachers accept that they do help improve the quality of education. ${ }^{24}$ Ramsden suggests that the process of setting aims (broad goals) and objectives (specific subject matter and learning outcomes) has a twofold 
purpose. Firstly, it enables teachers to think critically about student progress and how to connect it with what they teach. Secondly, it enables students to know what they have to learn to succeed..$^{25}$ The challenge in designing a substantive course that includes a mooting skills component is to mesh the different objectives.

A substantive tax course usually has objectives and learning outcomes relating to the substantive content. These objectives tend to focus on the knowledge or concepts that a student should understand, how the student obtains that understanding and how the student demonstrates that understanding. ${ }^{26}$ For example, a student might have to understand the concepts of capital and income and obtain that understanding through lectures and as a result of reading and analysing the relevant cases. The student might have to demonstrate that understanding during a discussion of a tutorial problem (the learning outcome).

The mooting component of a tax course has its own objectives and learning outcomes relating to the skills it is comprised of. The objectives and learning outcomes identify the skills that a student should acquire, how those skills are acquired and how the student should demonstrate those skills. The advantage of an integrated skills program is that the substantive and skills components can feed off each other while achieving their own objectives and learning outcomes. For example, a moot topic could focus on the difference between capital and income. Students acquire the substantive tax knowledge through lectures and through preparation for the moot. They acquire the mooting skills using the substantive subject matter. They then demonstrate the learning outcomes for both the substantive subject matter and the mooting component through their performance in each element of the moot.

Mackie puts forward a useful eight point plan that helps in matching the objectives of the skills component with the substantive subject objectives of a course. ${ }^{27}$ It could be seen as an expanded version of the three components identified in the MacCrate Report, above. The process helps teachers to identify the particular objectives and learning outcomes of the mooting program itself and enables its effective integration into the substantive tax course. A failure to match the skills training with the objectives and learning outcomes of the substantive tax course is likely to create a tension between the skills training component and the rest of the course content. Mackie's eight point plan is now applied specifically to a mooting program within a tax course to see how effective integration can take place. ${ }^{28}$

1. Establish learning objectives. ${ }^{29}$ As stated above, it is important at the outset to determine precisely what is to be learnt within the mooting program so that it can fit within the objectives of the substantive tax course..$^{30}$ This step encompasses the identification of the skills to be learnt and would include several of those skills identified above. Adapting the Statement of Fundamental Lawyering Skills and Professional Values of the MacCrate Report to a general tax context, some of the skills might be: problem solving, analysis and reasoning (covering both the legal and commercial aspects in the tax context); research; communication; dispute resolution procedures; aspects of work organisation and management; recognition and resolution of ethical dilemmas; and identification and application of professional values. The skills enumerated and the depth to which they can be explored depends very much upon the individual course and time and resource restraints. However, a mooting program could assist with the development of some or all of these skills. In addition to helping to achieve the substantive tax objectives relating to the particular subject matter chosen for the moot, the mooting program can also be particularly useful in helping to achieve substantive course objectives requiring an understanding of the tax administration process, more specifically relating to tax objections, appeals and the dispute resolution process. As already discussed, the mooting program then becomes an integral part of the course, through which much substantive technical knowledge can be learnt, instead of just being a skill, with its own independent objectives, added onto an existing course.

2. Identify the criteria for skilled performance. Just as it is vital to determine the overall objectives of any teaching program, so it is equally important to identify precisely the learning outcomes: what is expected of students. This is essential in determining how a program will be run, so that each element expected of a skilled performer is actually covered in the program. The students will generally concentrate their learning activities in attempting to meet those expectations. ${ }^{31}$ It also provides the opportunity for student ownership of the program, as students, in clarifying their understanding of what is expected, can be given a sense of negotiating the detail of the assessment criteria. Student 
involvement in this way has been shown to increase students' "motivation and engagement". 32 A simple identification of skilled performance criteria can be seen in the "Moot Marking Guide" shown at Appendix A. This guide is useful in that it provides a simple list of the required performance criteria, while showing students that it is precisely those criteria on which they will be marked. Experience suggests that students can become confused if they are given the assessment criteria and those criteria do not match exactly the criteria setting out the nature of a skilled performance. The confusion often rests in the interpretation, but identical lists of criteria are generally helpful in avoiding such problems.

3. Model effective performance. Practical examples tend to attract the attention of students more than theoretical discussion. Even more attention grabbing would be a video, modelling what this paper is trying to describe by showing a mooting program in action. That is no accident. Research has clearly demonstrated the importance of modelling a skill for enhanced learning. ${ }^{33}$ Accordingly, any mooting program should include modelling in some form. It can be either positive modelling, demonstrating how a moot and associated skills should be carried out, or negative modelling to exemplify behaviours to be avoided.

In most disciplines the moot will be part of an incremental skills program. In some schools/faculties the skills programs are advanced and each step in the program is measured and identifiable. ${ }^{34}$ In others, skills are seen as important and are included in the program, but are less clearly identified. In almost all programs in whatever discipline, by the time students enrol in a tax course, they will have acquired some basic skills from earlier courses. It is the extra element of the skills to be learnt in a tax program that will need specific modelling. Usually, this can be achieved within the teaching of the substantive elements of the course. For example, for commerce students who have no prior knowledge of legal library resources, it may involve a project early on in the course requiring use of the legal resources in the library to produce answers to questions on the substantive tax law. The project may be preceded by a brief segment in a tutorial, or in a special short class given by the librarian, that demonstrates the procedures to be followed in extracting relevant information from legal resource materials. There is the potential for each of the skills forming part of the mooting program to be modelled in this way. Use can be made of mooting videos, ${ }^{35}$ mooting manuals, ${ }^{36}$ marking guides, ${ }^{37}$ examples of summary arguments, and other resources to lighten the load of the instructors.

4. Provide opportunities to practise. Motivating students to learn is best achieved by their active engagement in the learning process. ${ }^{38}$ This is particularly so in the skills area. For many, resources are a problem. Mooting can be practised by the students with their mooting partners, if there are videos against which they can assess their achievement of the various competencies. Tutorials can be used for mooting practice. Not only does this add to the variety of teaching methods, but it gives the opportunity for students to practice important skills in the context of substantive knowledge. The slightly less formal tutorial setting can also reflect the more common real life contexts for the use of skills used in mooting: for example, communication of arguments to clients; fellow professionals; or the Australian Taxation Office.

5. Provide feedback. Feedback on performance is an essential part of the learning process. ${ }^{39}$ This is discussed in greater detail below.

6. Support progress towards the model. Support would be demonstrated through the evaluation and feedback process at each stage. An incremental practice program allows instructors to focus assistance on areas of weakness and to reinforce areas of strength.

7. Consolidation. Practice is the best means of consolidation. This is not always possible to any great extent within a single subject offering of a mooting program.

8. Repeat the earlier steps under different/more difficult conditions. Mooting generally takes place in a more formal court room setting; or can be adapted to represent proceedings before the Administrative Appeals Tribunal (AAT). Generally this form of simulation represents the final stage of the mooting program. The formality of the setting and the finality of the assessment make this a more difficult exercise of the skills than in practice sessions in moot groups or in tutorials. Accordingly, it provides students with the opportunity to demonstrate their mastery of the skills at the 
end of this segment of the skills program.

Mackie's eight point plan is useful in matching the objectives and learning outcomes of a substantive course with those for a skills program. Mooting within a tax program can clearly fit within the parameters of the plan. Time and resources will clearly limit the extent to which steps 4, 6 and 7 can be implemented, but a valid program can be constructed even within such constraints. Further comments on resource limitations are set out below. However, using this approach it is possible to conclude that mooting can be a valid method for developing the skills required of a tax professional, within a substantive tax course. It follows then that if the skills required by a tax professional can be developed using a mooting program, then mooting should be considered for integration into any substantive tax course, in whatever discipline the instruction takes place.

\section{PART II: A MOOTING MODEL}

The above analysis has shown that a mooting program can be used as a vehicle for the teaching of a wide range of skills, from basic library research skills to advanced advocacy. As the purpose of this paper is to set out how moots can be used in teaching undergraduate tax programs, this will be the main focus. It should be noted that the focus is from one particular perspective and readers will need to adapt what is only one model to suit their own circumstances and resources. However, the paper will have succeeded in its aim if it inspires anyone to use moots in their program for the first time, or acts as a stimulus for new ideas for readers with existing programs.

The model used in this paper is taken from the Bond University integrated skills program. ${ }^{40}$ There the skills program has developed using a process that flows easily from Mackie’s eight point plan: explanation, demonstration, application and actual practice, reflection and review, and repetition. ${ }^{41}$ The program is designed to try and ensure that there is a meshing of the learning objectives and outcomes of the skills modules and of the substantive subjects into which the skills modules are placed. ${ }^{42}$

The Bond program comprises a range of skills, including mooting, that are incorporated into substantive subjects across the degree program. The program is incremental in that it aims to ensure development of skills by students over the course of their degree. This means that from their first law subject right through to the end of their degree, law students will have to complete a skills component in a number of subjects that forms part of the skills program. As they progress through their degree their level of competency in each skill will develop. During a degree a student will normally complete at least four moots. As it happens, the tax moot is their final moot in the skills program.

It should also be noted that business and law students are taught tax together at Bond. This means that the moot has to be adapted for business students to take account of their lower level skills in mooting. This is discussed in more detail below, but it illustrates the fact that the mooting model used in this paper is flexible enough to be adapted for use in teaching students of different disciplines with different skill levels. $^{43}$

\section{The Extent of the Assessment}

Depending upon the subject and skill objectives of a course and their interplay, the extent of the assessment in a mooting program can vary tremendously and may even remain informal. However, given the range of skills that can be brought into play, it is important that the eight point plan outlined above, or some similar plan, is put into place to determine exactly what is to be achieved and how.

At one end of the spectrum the moot may form an integral part of an incremental skills program, as in the Bond skills program outlined above. In such a program the fundamental lawyering skills ${ }^{44}$ are taught as part of a stepped program of skill development over the course of a student's degree. The program has been carefully integrated into the substantive law program so that in coming to any course, the instructor will know the approximate level of skill development of students in the course and exactly which module of the skills program is to be covered in that course. In a typical incremental skills program each module is designed by a skills coordinator in conjunction with the course coordinator to ensure that: the objectives and methods are appropriate; the instructors are able to teach the skills to be covered; and the skills are taught in a way which will enhance, rather than detract from, the substantive content of the course. Teaching skills in 
an environment where skills training is part of the culture of the faculty makes it very much easier. However, this is not the position of most tax teachers.

The more common situation is for skills to be taught within an undergraduate degree program, but on a more ad hoc basis, with a specific focus on the traditional undergraduate skills of research and writing. Tax teachers are familiar with written assignments or projects containing problems to be solved. Any other skill development is up to the coordinator of the course, with little, if any, faculty support. Students come into the tax course at many different levels of skill development, which makes the use of skills as a form of assessment more difficult. Tax teachers in this position have to work harder to include different skills in their program. Generally in the context of severe time and resource constraints they have to develop a plan for implementation of their own course skills program and integrate it into the substantive content of the course. Although difficult, the results can be very worthwhile.

Another alternative, where there is little or no support and fewer resources to enable the integration of skills into a tax program, or where there are already other skills carefully integrated as part of the program, is to move to an informal approach. This may well be attractive for those who are unsure of their own ability to teach certain skills. It is possible to integrate skills on a very informal level in tutorials, for example. Instead of the debate that is a common technique for arousing interest in a tutorial, an informal moot could be used instead. The skill training could remain at this level or progress to a more formal level once instructors and students became familiar with the skill.

Acquiring skills in the first place can be difficult for teachers. A skills culture within a faculty makes it much easier. For example, the success of the Bond skills program depends upon each faculty member being trained to the appropriate level in the skill before they attempt to instruct in that skill. The training is given by those who are expert in the skills and has worked most effectively where the skill and instruction in the skill is modelled by the expert. The learner then co-teaches the skill with the expert before instructing on their own The process followed is effectively that set out in Mackie's eight point plan. ${ }^{45}$ For the majority of teachers who do not already possess the relevant skills, it is a question of self instruction using the literature, videos and other available resources. ${ }^{46}$ It is essential that skills instructors are themselves competent in the skills they want their students to develop, otherwise there is a strong risk that it "creates a situation of the blind leading the blind". 47

\section{Setting a Moot Problem}

The problem must be designed to meet the objectives of the course. This may entail the construction of a substantial problem, which can be used to develop basic library and research skills, writing skills, analytical skills and advocacy skills. However, tailoring a program that will enable students to learn all these skills is complex and is beyond the scope of this paper. Accordingly the model put forward here will concentrate on the moot itself.

For more informal moots run in tutorials, obviously the preparation and the process will be adjusted accordingly The setting of the moot is also flexible. A moot set in the AAT is often more useful to students than a courtroom setting. It is the forum with which tax professionals of all disciplines should be familiar, as they will have the most contact with it in practice. The conduct of a case in the AAT is less formal and, in the context of a tutorial program, can be part of a staged process. In conjunction with the development of substantive knowledge, procedural knowledge can be gained through a tutorial program incorporating the final negotiation of a tax audit, the conduct of a mediation, a preliminary conference of the AAT and finally the hearing of a case before the AAT. In order to move away from traditional teaching methods and incorporate new ideas into their teaching program, it is important for teachers to be prepared to adapt methods and processes to suit the particular objectives of their courses. Too often, a method is rejected outright, when with some modification it could be implemented to enhance the learning process in a course. ${ }^{48}$

As discussed above, skills development is most successful when it is grounded in the substantive content of a course. Experience has shown that the best moot problems are in areas where there is a reasonable amount of case law, preferably with competing views put forward by different courts or judges, or where there is a controversial case from a lower court or the AAT on a point that has not yet been heard in a higher 
court. These sorts of cases can be fruitful sources of moot problems, particularly if there are strong dissenting judgments. Cases where obiter comments have been made by a judge and subsequently opposed by the ATO in a Tax Ruling can also be useful. The problems can easily include policy arguments, as well as strictly technical arguments.

The basic principles of tax provide numerous scenarios for students to gain a deep understanding of the substantive concepts through a moot. It can also be interesting for the students to argue a case on appeal before the appeal is heard. They can then compare their arguments with the reasoning of the judges when the appeal judgments are handed down. Moot problems based upon sections of the legislation that have little or no case law to support arguments made, generally give too little material for the students to work with for a successful moot.

The key to setting a good moot problem is to try and ensure that the arguments are fairly evenly balanced, or at least that there are several arguments that can be made on each side of the issue. Problems, to be successful, need to be tied into the substantive content of the course. They can be used as a way to cover an area in depth, where there is not room to do so either in lectures or tutorials.

\section{The Preparation Process}

The structure of the moot will determine much of the preparation process for the student. Moots are usually argued by either one or two students on each side. Where there are two students there is more cooperation required between the students. This is a better representation of how files are worked on in legal or accounting practice and, as such, adds educational value to the exercise.

Where there is cooperation on moot submissions it is generally easier to provide valid assessment of an individual's contribution than it is in, say, a cooperative written assignment. This is because each student is required to submit arguments and can be questioned thoroughly on those submissions to test the student's own understanding of the tax law. Accordingly, the moot offers real opportunities to learn the skills required to work in a team, without prejudicing the instructor's ability to assess the performance of the individual student. ${ }^{49}$ The preparation period is where the skills of problem solving, legal analysis and reasoning, legal research and organisation and management of the work in hand, are fully utilised. Particularly for these skills, student cooperation can be a valuable tool for learning and improvement. ${ }^{50}$

It is important to provide a detailed set of instructions for the students with the moot problem, as discussed above at point 2 of Mackie's eight point plan. The instructions outline the criteria for skilled performance together with all the administrative details for the running of the moots.

One of the advantages of a tax moot over a written assignment is that the students are questioned upon their arguments. Accordingly, they need a real understanding of the tax law. They need to ascertain the material facts in the problem, identify the legal issues, their relevance and importance, and find the relevant cases. Further research has to be done to unearth any arguments on point raised by commentators, that may be raised by opposing counsel or the bench. Students have to determine the arguments for and against their case, be able to rebut the arguments for the other side and, because of time restraints, establish the priority of their arguments. A strategy has to be developed for their presentation, as to which arguments to present in which order. Students also need to rehearse their presentations in order to develop their oral communication skills.

\section{Submissions}

As part of the moot process it is useful for students to submit a summary of argument the day before the moot is heard and to provide opposing counsel with a summary of their argument and a list of the cases that they intend to cite at least 48 hours prior to their moot. Two functions are served by this. Firstly it ensures that counsel for both sides are aware of each others' arguments and allows the judge legitimately to question each side on the basis of the arguments raised by the other side. This gives students a taste of the type of procedures they will have to follow in practice. Secondly, it ensures that students have to identify their main arguments and how they will structure and prove them.

The weight of assessment given to the submissions can vary. They can be assessed independently from the moot as a written form of assessment or, alternatively, can form part of the overall assessment of the 
moot. Samples of a submission can be included in the moot instructions. This is part of the process of modelling effective performance, discussed above at point 3 of Mackie’s eight point plan.

\section{Assessment}

Assessment is necessarily subjective as it involves human judgment. The instructor is evaluating student learning: trying to determine what elements of the skills have been learned, what elements remain to be learned and what elements need further development. ${ }^{51}$ Integral to this is also the development and improvement of the instruction process. ${ }^{52}$

Ramsden states that assessment is a combination of a measure of a student's achievement of the objectives of a course and a comparison with other students in the same course or at a similar level. ${ }^{53}$ Certainly it would seem self evident that both are needed to achieve a valid and reliable assessment of mooting skills. Validity is found in the congruence between the learning objectives and the criteria for skilled performance, as set out in points one and two of Mackie's plan, above. ${ }^{54}$ Reliability is found in the consistency of assessment across the range of students assessed..$^{56}$ Once a form of assessment is valid and reliable, the fact that it is inevitably subjective is no longer at issue.

A sample copy of one possible moot marking guide is attached at Appendix A. ${ }^{56} \mathrm{By}$ listing a number of specific criteria in line with the objectives of the skills program, the guide provides the instructor with a tool to help make a valid assessment of each student's performance. It also facilitates a comparison with other students. From the students' perspective it represents an essential aspect of the clear articulation of the purposes of the course and the assessment methods to be used. Whatever assessment criteria are used, they should be made available to students at the earliest possible opportunity. ${ }^{57}$

In the Bond skills program, a copy of the moot marking guide is provided to students with the moot instructions. This is followed up with formal instruction on mooting, which specifically highlights the assessment criteria. So that students are familiar with what is meant by each of the criteria, they are also required to read a chapter on "advocacy" which forms part of the Bond University Skills Manual and to familiarise themselves with various in-house videos on learning to moot that model the skills as they are assessed. There are commercial texts and videos which can be used for this purpose..$^{58}$

A marking guide is a useful aid in the mooting process as it not only allows judges to note the performance of each student as measured against a number of specific criteria, but also provides for comments to enable the judge to explain why a particular mark was given, to expand upon strengths and weaknesses and to note down any other relevant factors. This provides the material from which the feedback can be given and on which the final assessment can be made. As noted, assessment includes a comparative element and a detailed marking guide allows a more valid and reliable comparison.

Mooting is also an effective method for testing the competence of students in relation to the substantive subject matter of the course. Dialogue between the judge and counsel provides the opportunity for instructors to assess higher level skills of analysis and evaluation rather than lower level skills such as recall of knowledge. ${ }^{59}$ This places an onus on the instructor to ensure that questions asked cannot be answered merely by recall.

In order to assist with consistency of marking across a wide range of moots it is very useful if the moots can be videotaped. The instructors can then refer back to a selection of moots to ensure that the marking has been consistent among instructors and across moots. A way to ensure consistency among instructors is for the instructors to sit on at least two moots together at the beginning of the mooting program so that they can compare their assessment of each student. This allows anomalies in marking styles or standards to be ironed out at the beginning, so that students are not disadvantage by there being different judges. The ideal would be for more than one judge to sit on each moot. However, resource restrictions will generally limit this form of double assessment for all students, much as they generally prevent marking of assignments and examination scripts by more than one instructor.

\section{Feedback}

Levis writes, "there is little contrary evidence to the general conclusion that learning is enhanced by frequent, immediate, and positive feedback. ${ }^{60}$ Levis goes on to say that the main effect of feedback is to 
reinforce successful action. ${ }^{61}$ He quotes Ausubel and Robinson, who say that feedback:

confirms appropriate meanings and associations, corrects errors, clarifies misconceptions and indicates the relative adequacy with which different portions of the learning task have been mastered. As a result of feedback, the subject's confidence in his learning products is increased, his learnings are consolidated, and he is better able to focus his efforts and attention on those aspects of a task requiring further refinement. ${ }^{62}$

Research has also shown, according to Levis, that feedback needs to be focussed and specific, highlighting important points for feedback, rather than making it general. ${ }^{63}$ This is where the moot marking guide is useful. It highlights the objectives seen as important in each student's perfomance and allows the instructor to focus on two or three areas in giving feedback. A specific focus is also beneficial when feedback is given, as students are generally suffering from the after effects of the stress of making their presentation. Further, it is argued that "students learn as much from listening to the critique of their peer's performances as they do from listening to the critique of their own presentation". 64

Given that feedback aims to reinforce appropriate behaviour as well as to point out errors, it is important to be balanced in giving feedback. There can be a tendency to focus on the faults of the presentation. Even where a student has performed abysmally, there will always be some positive point that can be reinforced. ${ }^{65}$ Equally important is to avoid personal criticism of students. ${ }^{66}$ To be effective, feedback should relate to behaviour that the student can improve and be couched in terms that the student can understand. ${ }^{67}$

Ideally each student should be provided with a copy of their marking guide with comments. This effectively means that the marking guide will need to be rewritten, as in a ten minute moot, where the judge is also asking questions, most of the notes on the original marking guide will be scribbled or in some form of shorthand. There is also the danger that, when marking guides are handed back with the numerical grading, students will compare and analyse the numerical grading in great detail and query even the slightest discrepancy, whether imagined or real. This misses the point of the marking guide, in that although as a checklist with a rating scale it should improve validity and reliability of assessment, assessment of “complex skilled performance will inevitably lean more towards impressionistic systems". ${ }^{8}$ Accordingly this needs to be explained to students and they should give appropriate weight to the comments at the bottom of the marking guide or an adapted form of the marking guide, without the numerical grading, should be given to the students. The restricted time that many instructors have for assessment of large numbers of students may mean that some teachers cannot provide the marking guides to students. In such cases, the feedback given immediately after the moot becomes more important.

Videotaping of moots is a further useful means of feedback. ${ }^{69}$ Time limitations will probably preclude the instructor from watching the videos with the students, but this has been found, in any event, sometimes to be a stressful experience for the students concerned. ${ }^{70}$ Self analysis has been found to be a very effective form of feedback, provided it is supported by some form of self evaluation guide or checklist, such as the moot marking guide. ${ }^{71}$

\section{Resource Implications}

The response to the MacCrate Report from US Law schools has centred in part on the resource implications of implementing a program that can teach the fundamental lawyering skills and values set out in the report. ${ }^{72}$ This is one of the main restrictions on the ability to use innovative forms of assessment, which tend to be more labour intensive.

Arguably however, a mooting program would take no more time than it would take to set and mark assignments. As four students can moot and be assessed in an hour, the load on each instructor in the course would not necessarily increase. A practical problem that might arise in any mooting program is that the number of students mooting may not be divisible exactly by four. Experience has shown that moots with odd numbers of students can work successfully. A further difficulty may be to fit in times and venues that are suitable. Provided students yet to moot are not permitted to hear the moots of earlier students, the moots can be run successfully over a number of weeks of the semester. There are added administrative requirements in terms of ensuring room allocations, organising and finalising a list of mooters, and, where videotaping is used, in ensuring the facilities are in place in the right rooms at the right times.

Overall, resources should not be a problem where interim assessment such as an assignment is currently used. However, if resource intensive interim assessment of some kind is not normally used in a course 
because of resource constraints, a formal mooting program is unlikely to be possible. An alternative is to use a less formal mooting program in the tutorial context. One way around the resource problem that has been found effective in the Bond program is to utilise the support of local practitioners, who are generally willing to provide their help without charge. For tax moots, the help of Australian Taxation Officers may also be available. Certainly, for teachers with several hundred students in a course with no tutorials or very large group tutorials scheduled, the use of mooting of any kind as a form of assessment is probably best left to advanced elective courses with smaller numbers. ${ }^{73}$

\section{Possible Problems}

There are any number of problems that may arise in a mooting program. Two, in particular, that could impact upon the effectiveness of the program are the participation of students from different cultural backgrounds and students starting from different skill bases.

Where there are students from different cultural backgrounds participating in the course, care needs to be taken if the assessment is to be fair to all students. ${ }^{74}$ Traditionally, resource limitations mean that teachers have not been able to provide the extra help that many overseas students need to adjust to an Australian educational environment. This has been so particularly in relation to assessment requiring oral communication skills. Accordingly there may be a need to schedule one or two extra classes to explain in more detail to students from non-Australian cultural backgrounds, exactly what is required of students in a moot. This should involve demonstration. Use of videotaped material to explain common errors and to emphasise good behaviours can work well to promote understanding.

In the moot itself, it is easy to reduce the marks given to foreign students because of poor spoken English or a heavy accent. It is important to concentrate on the presentation itself and what is being said, so that a fair assessment can be made. The marks in a moot are given not for skilled oratory, but inter alia, for a persuasive presentation of argument, evidence of a comprehensive grasp of the tax law and its application to a particular fact scenario. A student may be able to perform to the highest standards even with a heavy accent and using words in a slightly different way from the average Australian student. ${ }^{75}$

The problem of students starting from different skills bases can generally be solved. If the moot is assessing performance at a fairly low skills base, then the problem does not really arise. Those who come into the program with advanced skills will be at an advantage, much as anyone is coming into any program with prior knowledge. If the skills are being assessed at a higher level on the assumption that students have already attained a specific basic skills level, this is more of a problem. It may happen, for example, where a student transfers from another university where skills are not integrated into the program. In most cases the ordinary form of assessment cannot be changed to suit the student, as it is a requirement to pass the course. However, extra help can be given to such students in the form of advice and guidance as to technique, reading on the topic and other aids available.

Where students have different skill levels because they come from different degree programs there are other solutions. At Bond University, law and commerce students learn tax together. The skills program within the Law School emphasises mooting skills, so that law students studying tax should already have completed at least three moots. Commerce students do not generally moot as part of their program and, accordingly do not have the same skills in mooting as the law students. The solution used is to have all of the commerce students mooting together so that they can be assessed on the basis of the skill level at which they come into the program.

\section{Conclusion}

In the context of an increasing requirement for skills to be taught in undergraduate programs, it is important to identify those skills required by tax professionals. Little research has been done in this area in Australasia, but there is clearly an inter-disciplinary perspective, given the overlap between tax law and commercial business reality. Certain skills are required by most tax professionals and it then becomes the task of the tax teacher to determine how best students can acquire those skills during an undergraduate course of study.

Mooting offers one method of skills training. Although at first sight it appears law specific, the way it 
can be used to develop a broad range of the skills required by all tax professionals suggests that mooting can be used validly in commerce and business programs. It is a flexible method of skills training and can be used, for example, as a very formal roleplay of an appeal, a less formal hearing before the AAT, which nonlawyers need to be familiar with, or as a small group tutorial exercise. Mooting also has the major advantage of being no more resource intensive than the more usual forms of assessment, such as assignments or projects.

In the face of the increasing demands that will be put upon tax professionals to provide comprehensive, value added service to their clients, it makes sense for tax students to be given the best possible opportunities to acquire the skills that they will need in practice. There is also the added pressure that will be placed upon tax professionals to represent their clients in the increasingly informal fora for resolving tax disputes, such as the AAT and the Small Tax Claims Tribunal. Alternative methods of dispute resolution are becoming popular, which will lead to an increase in the teaching of skills such as negotiation and mediation in undergraduate tax courses. Many of the skills required are also those required in a moot. Students who have mooted and improved their skills as a result should be better equipped to practice as tax professionals. ${ }^{76}$

\section{APPENDIX A}

\section{Moot Marking Guide}

$1=$ very unsatisfactory, $2=$ unsatisfactory, $3=$ average, $4=$ good,

$5=$ excellent

\section{COURTROOM FORMALITIES}

Courtroom etiquette

Opening

Closing

Presentation

Communication Skills

ABILITY TO ENTER DIALOGUE

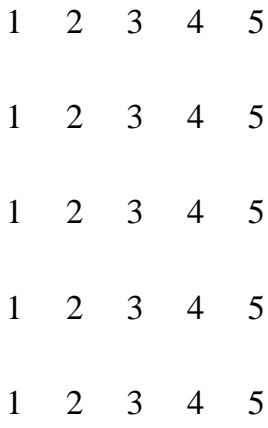
5

Read/heavy reliance on notes

$\begin{array}{lllll}1 & 2 & 3 & 4 & 5\end{array}$

Ability to respond satisfactorily to $\begin{array}{lllll}1 & 2 & 3 & 4 & 5\end{array}$ questions without having to search through notes

$\begin{array}{llllll}\text { Ability to answer questions even when they } & 1 & 2 & 3 & 4 & 5\end{array}$ did not relate directly to the point being presented

Ability to resume argument $\begin{array}{lllll}1 & 2 & 3 & 4 & 5\end{array}$

\section{QUALITY OF ARGUMENT}


Stated correctly relevant principles of law

$\begin{array}{lllll}1 & 2 & 3 & 4 & 5\end{array}$

Applied principles to facts

$\begin{array}{lllll}1 & 2 & 3 & 4 & 5\end{array}$

Distinguished relevant cases

$\begin{array}{lllll}1 & 2 & 3 & 4 & 5\end{array}$

Evidence of research

$\begin{array}{lllll}1 & 2 & 3 & 4 & 5\end{array}$

Completeness of argument

$\begin{array}{lllll}1 & 2 & 3 & 4 & 5\end{array}$

Argued in accordance with summary

$\begin{array}{lllll}1 & 2 & 3 & 4 & 5\end{array}$

submitted

\section{WRITTEN SUBMISSION}

Submitted to Level 3 Box the day before

$\begin{array}{lllll}1 & 2 & 3 & 4 & 5\end{array}$

moot

Correct form of case citations

$\begin{array}{lllll}1 & 2 & 3 & 4 & 5\end{array}$

Citation of relevant cases

$\begin{array}{lllll}1 & 2 & 3 & 4 & 5\end{array}$

Concise summary of key points and

$\begin{array}{lllll}1 & 2 & 3 & 4 & 5\end{array}$

argument

Other comments

* Assistant Professor, School of Law, Bond University (C) 1996. (1996) 7 Legal Educ Rev, 97.

1 D Pearce, E Campbell \& D Harding, Australian Law Schools: A discipline assessment for The Commonwealth Tertiary Education Commission - A summary (Canberra: AGPS, 1987) 30.

2 Id at 31.

3 American Bar Association, Law Schools and Professional Education: Report and Recommendations of the Special Committee for a Study of Legal Education of the American Bar Association (Chicago: ABA, 1980) 45.

4 Id.

5 Id at 46.

6 American Bar Association, Legal Education and Professional Development - An Educational Continuum: Report of The Task Force on Law Schools and the Profession: Narrowing the Gap (MacCrate Report) (Chicago: American Bar Association, 1992) [referred to as MacCrate Report].

7 R Kreitner \& A Kinicki, Organizational Behaviour (Homewood Ill: BPI Irwin, 1989) 487.

8 C Engel, Not Just a Method But a Way of Learning, in D Boud \& G Feletti eds, The Challenge of Problem Based Learning (London: Kogan Page, 1991) 26. See also on alternative models, HS Barrows \& RM Tamblyn, Problem-Based Learning: An Approach to Medical Education (New York: Springer, 1980); DA Schon, The Reflective Practitioner (San Francisco: Basic Books, 1983); and DA Schon, Educating the Reflective Practitioner (San Francisco: Jossey-Bass, 1991).

9 C. Schwenk, The Use of Participant Recollection in the Modeling of Organizational Decision Processes (1985) Academy Mgmt Rev 496.

10 Kreitner \& Kinicki, supra note 7, at 499.

11 S Neales, Into the 21st Century (1994) 65 Charter 14, at 15.

12 W Twining, “Taking skills seriously” in N Gold, K Mackie \&W Twining eds, Learning Lawyers' Skills (London and Edinburgh: Butterworths, 1989) 4.

13 Professor of Law, Victoria University of Wellington, leading international tax academic and consultant.

14 J Prebble, International Tax Education (1995) 5 Revenue LJ 151.

15 C McInnes \& S Marginson, Australian law schools after the 1987 Pearce Report (Canberra: AGPS, 1994$)$ ch 16.

16 MacCrate Report, supra note 6, at 245.

17 E Robertson, Teaching and Related Activities, in MJ Dunkin ed, The International Encyclopedia of Teaching and Teacher Education (Sydney: Pergamon Press, 1988) 16.

18 RE Sutton \& RH Ennis, Logical Operations, in MJ Dunkin, id 380 at 385.

19 Prebble, supra note 14, at 153. 
20 Sutton \& Ennis, supra note 18, at 389.

21 Pearce, Campbell \& Harding, supra note 1, at 36 provides clear evidence of this in its evaluation of law schools' LLB programs and teaching.

22 NA Flanders, Human Interaction Models, in MJ Dunkin, supra note 17, at 23, referring to BR Joyce \& M Weil, Models of Teaching (New Jersey: Prentice-Hall, 1980) 105. See also, K Mackie, Lawyers' skills: educational skills, in Gold, Mackie \& Twining, supra note 12, at 19.

23 MacCrate Report, supra note 6, at 243.

24 P Ramsden, Learning To Teach In Higher Education (London: Routledge, 1992) 129; M Le Brun \& R Johnstone, The Quiet (R)evolution (Sydney: The Law Book Company Limited, 1994) ch 4; W Twining, supra note 12, at 14; and JB Biggs \& R Telfer, The Process of Learning 2nd ed (Sydney: Prentice-Hall, 1987) 521.

25 Ramsden, id at 130. For a comprehensive discussion and reference to major research in this area, see Le Brun \& Johnstone, id.

26 Ramsden, id.

27 Mackie, supra note 22, at 20.

28 That skills objectives can be integrated successfully into substantive law programs is discussed further in numerous articles, including: D Bentley, Using Structures to Teach Legal Reasoning (1994) 5 Legal Educ Rev 129; L McCrimmon, Trial Advocacy Training in Law School: An Australian Perspective (1994) 5 Legal Educ Rev 1; K Mack, Bringing Clinical Learning into a Conventional Classroom (1993) 4 Legal Educ Rev 89.

29 If, in considering Mackie's eight point plan in relation to a moot in a substantive tax subject, readers would prefer first to have a clearer understanding of the context in which this could take place, reference should be made to the discussion at the beginning of Part II of this paper.

30 The process of writing objectives and establishing learning outcomes is the subject of useful discussion by Ramsden, supra note 24, at ch 8 and Le Brun \& Johnstone, supra note 24, at ch 4.

31 Id.

32 Le Brun \& Johnstone, id at 189.

33 MacLeod summarises some of this research in his article: GR MacLeod, Microteaching: Modelling, in Dunkin, supra note 17, at 720 .

34 For example, in the law and business programs at Bond University.

35 There are commercial examples available, for example the video cassette from Deakin, Moot Court: an integral part of legal education at Deakin University (Geelong: Deakin 1993).

36 For example, T Gygar \& A Cassimatis, Mooting Manual (Butterworths — forthcoming).

37 For example, see appendix A.

38 Ramsden, supra note 24 , at 100.

39 Id at 99.

40 For a detailed description and analysis of this program refer to K Lauchland, The Integration of Skills Training Into The Substantive Law Program: The Bond Method, paper presented to the 14th LAWASIA Biennial Conference, Beijing. China, 16-20 August 1995. For papers dealing with detailed aspects of this program, see Bentley, supra note 28, McCrimmon, supra note 28, JH Wade, Meet MIRAT Legal Reasoning Fragmented into Learnable Chunks (1990-91) 2 Legal Educ Rev 283 and B Bott, Law Library Research Skills Instruction For Undergraduates at Bond University: the Development of a Programme (1994) 5 Legal Ed Rev 118. For a different model of an integrated skills program used at Griffith University, see for a discussion of different aspects, M Le Brun, Law at Griffith University: The First Year of Study (1992) 1 Griffith L Rev 15, B Dick, L Godden, K Healy \& MJ Le Brun with G Airo-Farulla \& D Lamb, A Case Study of the 'Offices' Project (Teacher-Less, Cooperative Learning Groups) at Griffith University: Implementing Educational Theory (1993) 4 Legal Educ Rev 273 and S Kift \& G Airo-Farulla, Throwing Students in the Deep End, or Teaching Them How to Swim? Developing 'Offices' as a Technique of Law Teaching (1995) 6 Legal Educ Rev 53.

41 Lauchland. id at 4.

42 The approach reflects the fact stated by Mack, supra note 28, at 95, in the context of clinical legal education, that it helps us to "understand the unbreakable nexus between substantive law, legal process and lawyer tasks and between theory and practice".

43 A similar model has been adapted very successfully for use in a tax course in an accounting context by Brett Herbert at the University of New England.

44 MacCrate Report, supra note 6.

45 Lauchland, supra note 40, at 23.

46 For example, Deakin, supra note 35, and Gygar, supra note 36.

47 W Noel Keyes, Approaches and Stumbling Blocks to Integration of Skills Training and the Traditional Methods of Teaching Law (1980) 29 Clev St L Rev 685 at 688.

48 Feedback and discussion on this point was gratefully received by the writer in response to a paper presented at the 1996 Australasian Tax Teachers' Conference.

49 For discussion of the importance of promoting student-student cooperation, see L Owens, Cooperation, in Dunkin, supra note 17 , at 345. The assumption here is that, because of lack of resources, the opportunity for the individual assessment required in most undergraduate courses is more important to the instructor than a group assessment. For an example of the successful use of group assessment in an undergraduate program see Dick, Godden, Healy \& Le Brun, with Airo-Farulla and Lamb, supra note 40.

50 Owens, id.

51 KE Eble, The Craft of Teaching 2nd ed (San Francisco: Jossey-Bass, 1990) 144.

52 Ramsden, supra note 24, at 186.

53 Ramsden, id at 187 . For a discussion of what we should be aiming to achieve through assessment and feedback, see also JW Barnes, 'The Functions of Assessment: A Re-examination (1990-91) 2 Legal Educ Rev, 177.

54 Mackie, supra note 22, at 20. An interesting study on assessment in American Law Schools was conducted by M Josephson for the Association of American Law Schools, Learning \& Evaluation in Law School (Los Angeles: Loyola, 1984).

55 Mackie, id at 21 and Josephson, id at 15.

56 The marking guide has been used successfully by a number of instructors in the Bond skills program. 
57 Research has shown that, particularly in the skills areas, making assessment criteria explicit and public is likely to enhance student learning. See, for example, Ramsden, supra note 24, at 188, Mackie, supra note 22, at 14, and Le Brun \& Johnstone, supra note 24, at 154 .

58 See, for example, Deakin, supra note 35; Gygar, supra note 36; G McGinley, Mooting and Advocacy and Other Lawyering Skills, in JF Corkery ed, A Career in Law (Leichhardt: Federation Press, 1989) 174; and E Kingston Braybrooke, Moot Court, in R Krever ed, Mastering Law Studies and Law Exam Techniques (Sydney: Butterworth, 1990) 88.

59 These concepts of different levels of cognitive activity were developed by BS Bloom, MB Engehart, EJ Furst, WH Hill \& DR Krathwohl in Taxonomy of Educational Objectives of Cognitive Domain (New York: McKay, 1956) and have been alluded to or discussed in most books and articles on assessment since. For an interesting article containing recent research on students' perspective of assessment, see N Rogers, Improving the Quality of Learning in Law Schools by Improving Student Assessment (1993) 4 Legal Educ Rev 113.

60 DS Levis, Microteaching: Feedback, in Dunkin, supra note 17, at 723. See also, the useful section on "Feedback to Students" in Ramsden, supra note 24, at 193.

61 See also, JA Bates, Reinforcement, in Dunkin, supra note 17 at 349.

62 DP Ausubel \& FG Robinson, School Learning: An Introduction to Educational Psychology (New York: Holt, Rinehart \& Winston, 1969) 299, quoted in Levis, supra note 60, at 723.

63 Levis, id.

64 McCrimmon, supra note 28 at 10, describing the feedback methods used by the National Institute for Trial Advocacy in the United States.

65 Ramsden, supra note 24, at 194.

66 Id and McCrimmon, supra note 28 at 10.

67 Id and Le Brun \& Johnstone, supra note 24 at 219.

68 Mackie, supra note 22, at 22.

69 See further, McCrimmon, supra note 28, at 10, for a brief but useful discussion of the use of video review.

70 Levis, supra note 60.

71 Id. Le Brun \& Johnstone, supra note 24, throughout their book suggest that teachers should be emphasising self-assessment to enable students to take responsibility for their own learning.

72 JJ Costonis, The MacCrate Report: Of Loaves, Fishes, and the Future of American Legal Education (1993) 43 J Legal Educ 157; R MacCrate, Preparing Lawyers to Participate Effectively in the Legal Profession (1994) 44 J Legal Educ 89; and J Stark, Dean Costonis on the MacCrate Report (1994) 44 J Legal Educ 126.

73 Many teachers of commercial law subjects such as tax are in this position. This point was strongly made in discussion groups at the 1996 Australasian Tax Teachers' Conference.

74 For a discussion on equity and access considerations, see Le Brun \& Johnstone, supra note 24, at 63.

75 For an excellent, readable guide to teaching foreign students, see B Ballard \& J Clanchy, Teaching Students from Overseas (Melbourne: Longman Cheshire, 1991). See also the useful article by DJ Phillips, Solutions to the Dilemmas and Concerns of Teaching International Students in Universities (1994) 5 Legal Educ Rev 47.

76 Pearce, Campbell \& Harding, supra note 1; the MacCrate Report, supra note 6; and Neales, supra note 11. 